\title{
How faculty define quality, prestige, and impact in research
}

\author{
Esteban Morales*1, Erin McKiernan ${ }^{2}$, Meredith T. Niles ${ }^{3}$, Lesley Schimanski ${ }^{4}$, Juan Pablo \\ Alperin*4 \\ 1. University of British Columbia, Canada. \\ 2. Universidad Nacional Autónoma de México \\ 3. University of Vermont \\ 4. Simon Fraser University \\ ${ }^{*}$ Corresponding authors
}

\begin{abstract}
Despite the calls for change, there is significant consensus that when it comes to evaluating publications, review, promotion, and tenure processes should aim to reward research that is of high "quality," has an "impact," and is published in "prestigious" journals. Nevertheless, such terms are highly subjective and present challenges to ascertain precisely what such research looks like. Accordingly, this article responds to the question: how do faculty from universities in the United States and Canada define the terms quality, prestige, and impact? We address this question by surveying 338 faculty members from 55 different institutions. This study's findings highlight that, despite their highly varied definitions, faculty often describe these terms in overlapping ways. Additionally, results shown that marked variance in definitions across faculty does not correspond to demographic characteristics. This study's results highlight the need to more clearly implement evaluation regimes that do not rely on ill-defined concepts.
\end{abstract}

\section{Financial Disclosure}

Funding for this project was provided to JPA, MTN, ECM, and LAS from the OpenSociety Foundations (OR2017-39637). The funder had no role in study design, data collection and analysis, decision to publish, or preparation of the manuscript.

\section{Related Materials}

Other publications related to this project, including a series of infographics summarizing findings, can be found at: https://www.scholcommlab.ca/research/rpt-project/

Survey responses can be found at the following publication:

Niles, Meredith T.; Schimanski, Lesley A.; McKiernan, Erin C.; Alperin, Juan Pablo,2020, "Data for: Why we publish where we do", https://doi.org/10.7910/DVN/MRLHNO, Harvard Dataverse, V1

Data regarding RPT documents can be found at the following data publication:

Alperin, Juan Pablo; Muñoz Nieves, Carol; Schimanski, Lesley; McKiernan, Erin C.;Niles, Meredith T., 2018, "Terms and Concepts found in Tenure and Promotion Guidelines from the US and Canada", https://doi.org/10.7910/DVN/VY4TJE, Harvard Dataverse, V3, UNF:6:PQC7QoilolhDrokzDPxxyQ== [fileUNF] 


\section{Introduction}

Although faculty work involves a wide range of activities and priorities (Fox, 2012; Gruzd et al., 2011; Miller \& Seldin, 2014), evidence confirms that faculty, even those at teaching and public institutions, believe that research is the most highly valued aspect of their work (Acker \& Webber, 2016; Bergeron et al., 2014; Harley et al., 2010). It is therefore unsurprising that despite significant efforts to broaden how university faculty are assessed, research continues to be treated as the main component of a professor's job (Chen, 2015; Gordon, 2008; Harley et al., 2010) and, accordingly, research assessment features prominently in how faculty are evaluated for career advancement. Yet, despite its perceived importance and critical role, there is still debate about how to evaluate research outputs.

Research assessment, which is codified for faculty career progression in review, promotion, and tenure (RPT) processes, is itself a controversial topic that has been subject to much debate over the years (c.f., Schimanski \& Alperin, 2018). Critics have argued that current assessment practices fail to recognize new and evolving forms of scholarship, such as datasets and research software (Genshaft et al., 2016; Howard, 2013; Piwowar, 2013; Sanberg et al., 2014), fail to encourage reproducible science (Open Science Collaboration, 2015), or worse, that current approaches encourage unethical practices, such as gift authorship, p-value hacking, or result manipulation (Chapman et al., 2019; Edwards \& Roy, 2017). These discussions point to different perspectives regarding what constitutes research that is worthy of being celebrated and rewarded.

Despite the calls for change and the differences of opinions, there is significant consensus that when it comes to evaluating publications, the RPT process should aim to reward research that is of high "quality" and has "impact" (Schimanski \& Alperin, 2018). However, such terms are highly subjective, and present challenges to ascertain precisely what such research looks like. Furthermore, their subjectivity presents additional challenges for comparing research and individuals, as is regularly done during the RPT process. The use of these subjective concepts, and others like them, may serve primarily as "rhetorical signalling device[s] used to claim value across heterogeneous institutions, researchers, disciplines, and projects rather than a measure of intrinsic and objective worth" (Moore et al., 2017, p. 3). and concepts used in research assessment (Dean et al., 2016; Hatch, 2019; Moore et al., 2017; 
van Mil \& Henman, 2016). Without definitions, individuals and committees are bound to apply different standards which inevitably leads to inequities in how faculty and research are evaluated. If, as Hatch (2019) suggests, "most assessment guidelines permit sliding standards," then the definition used in any given situation can easily shift depending on whose work is being assessed in ways that allow (or even encourage) biases to creep into the evaluation process (be they conscious or unconscious). Even if individuals are consistent and unbiased in how they apply their own definitions, there is rarely agreement in assessments between academics, even from those of the same discipline. Moore and colleagues (2017) point to such conflicting assessments as the clearest example of a lack of any agreed upon definition of 'excellence'-an argument that can easily be extended to other terms and concepts commonly used in research assessment.

The known pernicious effects of using ill-defined criteria has resulted in calls to "swap slogans for definitions" (Hatch, 2019) and for greater "conceptual clarity" (Belcher \& Palenberg, 2018) in research assessment. To aid in this effort, this study asks the question: how do faculty understand the concepts of 'quality', 'impact', and 'prestige' as they pertain to RPT processes?

\section{Previous research}

The current study builds on our previous work to study the documents related to RPT processes at institutions in the United States and Canada (Alperin et al., 2019; McKiernan et al., 2019; Niles et al., 2020), as well as similar work by others in this area (Moher et al., 2018; Rice et al., 2020; Snider et al., 2020). In one of our previous studies (Alperin et al., 2019), we reported that nearly $60 \%$ of institutions overall and nearly $80 \%$ of research-intensive universities mentioned 'impact' in their RPT documents. Using the same data and analysis, but previously unreported, we also found that $73 \%$ of institutions in our sample and $89 \%$ of research-intensive universities mentioned 'quality' in their RPT documents, and that those percentages were $29 \%$ and $47 \%$ for those that mentioned 'prestige.' That is to say, there was a high prevalence of such concepts in academic evaluations, but a closer reading of these instances shows that few of these documents gave a clear definition of what these terms meant or how they were to be measured.

Despite the frequent use of these terms in relation to research assessment, it is difficult to know how faculty understand them, especially in relation to how they will assess others, and in how they understand that they will be assessed. A survey by DeSanto and Nichols (2017) 
1 found that "... a significant number of faculty [are] unsure of their department's RPT expectations

2 for demonstrating scholarly impact" (pg. 156). Results from that same study show there is

3 substantial disagreement among faculty as to how impact should be measured and evaluated,

4 with many pushing for traditional journal-level metrics like the Journal Impact Factor (JIF) and a

5 small percentage favoring new article-level metrics and altmetrics. Similarly, there is

6 disagreement as to how research quality should be measured, with little evidence suggesting

7 that it can be assessed through citation-based metrics like the JIF (Aksnes et al., 2019). In lieu

8 of an objective measure of quality, it has become common to use the perceived prestige of the

9 publication venue (i.e., the journal where an article is published) as a proxy. To confound things

10 further, prestige is itself sometimes associated with the JIF (e.g., Vinyard \& Colvin, 2018), even

11 while the association of the JIF with both quality and prestige has been heavily criticized, most

12 notably in The San Francisco Declaration on Research Assessment (Cagan, 2013; DORA,

13 n.d.), the HuMetricsHSS Initiative (n.d.) and in the Leiden Manifesto (Hicks et al., 2015).

This interplay between the JIF, quality, impact, and prestige and how it features in research assessment is also evident when faculty make decisions about where to publish their research. A recent faculty survey (Blankstein \& Wolff-Eisenberg, 2019) shows that nearly $80 \%$ of faculty report the JIF as one of the most important factors influencing their decisions on where to publish, something echoed in our own survey findings (Niles et al., 2020). In some instances, faculty are guided by librarians to use the JIF to determine the prestige of a given journal (Vinyard \& Colvin, 2018) but, according to the same Ithaka survey, the majority of faculty make such decisions based on their own perceptions of the quality, prestige, and potential impact of a given journal. As the report states: "less than $20 \%$ of respondents reported they receive help...determining where to publish to maximize impact, and assessing impact following publication" (Blankstein \& Wolff-Eisenberg, 2019, p. 27).

These surveys show that, when it comes to making decisions about where to publish, faculty see an interplay between the notions of impact, quality and prestige and have themselves linked these to metrics like the JIF, although their precise understanding of these terms remains unclear. To some extent, these interconnected concepts have been codified in the RPT guidelines and documents that govern academic careers. As noted above, in previous work we uncovered the high incidence of the terms quality and impact in these documents (Alperin et al., 2019) and, in another study, we uncovered that the JIF and related terms are found in the RPT documents of $40 \%$ of R-type institutions, and the overwhelming majority of those mentions support their use (McKiernan et al., 2019). Similarly, Rice et al. (2020) found 
mentions of the JIF in nearly $30 \%$ of the RPT guidelines from several countries, and also found

support for the measure's use. Moreover, we found that although it is not always stated what the

JIF is intended to measure, $63 \%$ of institutions that mentioned the JIF in their documents had at least one instance of associating the metric with quality, $40 \%$ had at least one mention associating it with impact, and $20 \%$ with prestige (McKiernan et al., 2019). These results are in stark contrast to a number of studies showing that JIF has little or nothing to do with research quality (Brembs, 2018; Fraley \& Vazire, 2014; Munafò et al., 2009; Szucs \& loannidis, 2017).

The complexity of these terms, intertwined with their application in faculty behavior and promotion decisions, demonstrate a need to further understand how faculty themselves perceive these terms. Their persistent use in both publication decisions and in research assessment indicates their importance and the ambiguities, regardless of their reason for being, suggest that further study is needed. As such, we sought to answer the question: how do faculty from universities in the United States and Canada define the terms quality, prestige, and

14 impact?

\section{Methods}

As part of the larger project (Alperin et al., 2019; McKiernan et al., 2019; Niles et al., 2020), we collected documents related to the RPT process from a random sample of universities in the United States and Canada. We describe the methods and considerations used when selecting institutions, the process for identifying the documents, and the approach used to identify the presence of terms in Alperin et al. (2019) and in the methodological note accompanying the public dataset (Alperin et al., 2018). To summarize, we followed a stratified sampling technique to identify a representative set of universities from two lists: the 2015 edition of the Carnegie Classification of Institutions (n.d.) and the 2016 edition of the Maclean's Rankings (n.d.). Both lists, using slightly different definitions and nomenclature, allowed us to draw from three types of institutions: those that award many doctoral degrees and are researchintensive (R-type), those that award many master's degrees but few or no doctoral degrees (M-

27 type), and those that award few graduate but many undergraduate (baccalaureate) degrees (B28 type)., and those that focus on undergraduate programs (i.e., baccalaureate; B-type). We then 29 used a combination of web searches, requests on social media, and targeted emailing to collect 30 documents related to the RPT process. 
Through this process, we collected a total of 859 documents, including faculty handbooks, collective agreements, memos and forms. The documents corresponded to 129 institutions, of which 57 were R-type, 39 were M-type, and 33 were B-type institutions. While some documents applied to the institution as a whole (e.g., collective agreements), other documents were from a specific academic unit (i.e., a department or faculty). The final set contained documents from 381 distinct academic units, themselves a part of 60 of 129 universities.

As described in more detail in McKiernan et al., (2019), we used text queries with QSR International's NVivo 12 qualitative data analysis software to search every document for terms related to the JIF, including "impact factor", "impact score", "impact metric", "impact index", "high-impact journal", "impact of the journal" and "journal('s) impact." We considered that an academic unit mentions the JIF if we were able to find any of the related terms mentioned in at least one of the documents from that unit.

In addition, and as described in greater detail in Niles et al. (2020), we took the list of the 381 academic units for which we had at least one document and conducted a web search for a page containing a listing of faculty members from each unit. From these, we picked up to five members from the list without considering the individual's characteristics or their position in the list. We were able to identify 1,644 faculty email addresses from 334 of the 381 academic units. Although some units did not have their faculty email addresses listed publicly, and others did not have 5 faculty members listed, we were able to obtain email addresses for at least one unit at each of the 60 universities on our list.

We took this list of email addresses and invited faculty to participate in a survey between September and October 2018. We received responses from 338 faculty (22\%) from 55 different institutions. Of these, 84 (25\%) were faculty at Canadian institutions and the remaining 254 (75\%) were from the United States; 223 (66\%) were from R-Type institutions, 111 (33\%) from M-Type institutions, and 4 (1\%) from B-Type institutions. Full methodological details and demographic reporting of respondents can be found in Niles et al. (2020).

In this paper, we present a detailed analysis of the 336 responses to the question "In your own words, how would you define the following terms, sometimes used to describe academic journals?" The terms included in this question were high quality, prestigious and high impact. We analyzed the responses using open-coding and constant comparison (Strauss \& 
1 Corbin, 1990). To achieve this, we first organized all the responses into segments-sentences,

2 or parts of sentences, that convey a single idea. We then assigned codes to these segments,

3 grouping those that represent the same idea or creating new codes when a new idea appeared.

4 Each response could contain one or multiple segments, each of which could be coded

5 differently, allowing for a single response to have multiple codes. This process continued until

6 we developed a codebook that included the name of the codes, descriptions for each and

7 examples, as shown in Tables 1, 2 and 3 (below, in the results section).

In order to determine the inter-rater reliability of the codebook, two researchers

9 independently coded the same randomly chosen set of 20 responses for each of the three

10 terms, and compared the results using NVivo 12, which resulted in adjustments to the codebook

11 and finally an overall Kappa value of 0.87 (McHugh, 2012). After having a good result in the

12 inter-rater reliability test, all the responses were coded by one of the authors of this study (EM).

13 Finally, the results of the open-coding process were analyzed by running Chi-Square tests upon

14 different variables in Excel, in order to see the variation of the definitions in the light of different 15 categories.

\section{Results}

We present the results in three parts: first, we describe the results of the open-coding process for the three terms, as the codes themselves capture the definitions used by respondents; second, we analyze the frequencies of each code in relation to respondent's demographic information; and, finally, given the high incidence of the JIF in faculty definitions of the three terms, we explore the relationship between faculty definitions and the presence of the JIF in the RPT guidelines at the faculty member's institution and academic unit.

\section{Defining quality, prestige and impact}

The analysis of the definitions provided for high quality resulted in 295 segments. These segments were categorized into five groups: Impact factor and Metrics, Value, Readership, Reputation, and Review Process. Table 1 provides the description of each group, as well as some examples for each of them.

The result of this coding process shows that faculty most commonly define high quality based on the review process, referring to the perceived rigor of the process of evaluating, gatekeeping and editing academic articles for the journal (e.g., "rigorous review and selection of 
articles to publish" [848]) (Figure 1). Another common view on what determines the quality of an academic journal is related to the perceived value of the articles published within it, including

3 how consequential they are for the field, the quality of the writing, and the methodological

4 standards of the research (e.g., "Good methodology, quality writing" [1624]).

5 Table 1. Categories identified in the definitions of High Quality.

6 Name, description and examples of the categories found in participants' definitions of High Impact. Numbers in 7 square brackets represent anonymized identification of participants.

\begin{tabular}{|c|c|c|}
\hline Category & Description of the category & Examples \\
\hline Impact factor and metrics & $\begin{array}{l}\text { Established measurement for } \\
\text { the journals by the articles that } \\
\text { are published, and the citation } \\
\text { generated }\end{array}$ & $\begin{array}{ll}\text { - } & \text { High journal ranking [373] } \\
\text { - } & \text { Journal impact factor [500] }\end{array}$ \\
\hline Value & $\begin{array}{l}\text { Quality and applicability of the } \\
\text { articles published in the journal, } \\
\text { including its scientific rigor and } \\
\text { contribution to the field }\end{array}$ & $\begin{array}{l}\text { - Quality of the research being } \\
\text { presented [582] } \\
\text { - Publishes well-researched, } \\
\text { innovative articles [703] }\end{array}$ \\
\hline Readership & $\begin{array}{l}\text { Focuses on how much the } \\
\text { published work is read by } \\
\text { academic and non-academic } \\
\text { people }\end{array}$ & $\begin{array}{l}\text { - } \quad \text { Large readership [62] } \\
\text { - Is widely read [621] }\end{array}$ \\
\hline Reputation & $\begin{array}{l}\text { Influence and recognition of all } \\
\text { the elements related to the } \\
\text { journal, such as the editorial } \\
\text { board, the scholars who publish } \\
\text { or the journal itself }\end{array}$ & $\begin{array}{l}\text { - Well-established, well-known } \\
\text { editorial board [568] } \\
\text { - name recognition of journal [162] }\end{array}$ \\
\hline Review process & $\begin{array}{l}\text { Elements related to the process } \\
\text { of reviewing the articles that are } \\
\text { published, such as editors, } \\
\text { feedback and rejection rate. }\end{array}$ & $\begin{array}{l}\text { - Peer-reviewed publication [1610] } \\
\text { - Rigorous, reviewed by top } \\
\text { reviewers in the field [600] }\end{array}$ \\
\hline
\end{tabular}




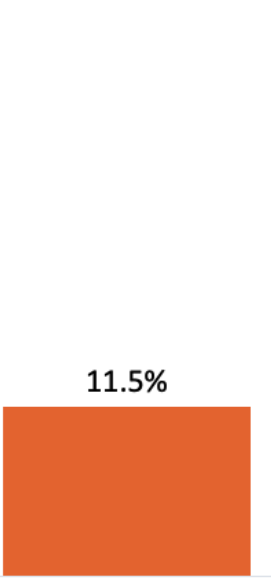

Impact factor and metrics

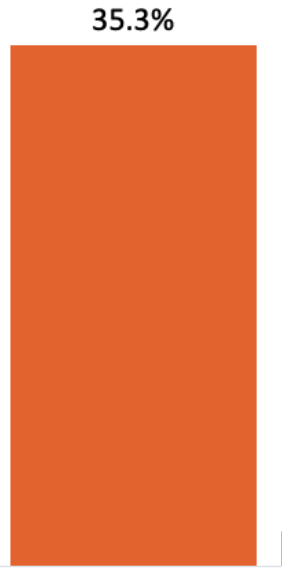

Value

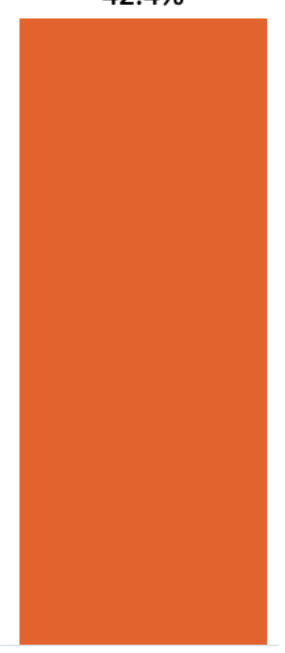

Readership
$8.5 \%$

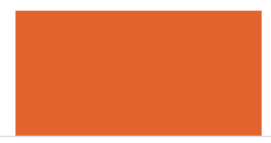

Reputation
Review process

3 Figure 1. Definitions of High Quality.

4 Percentage of responses that contained at least one segment in each of the categories identified in participants' definitions of High Quality.

The analysis of the definitions provided for prestige resulted in 262 segments. These segments were coded under six categories: Impact Factor and Metrics, Quality and Relevance, Readership, Relation to Associations, Reputation, and Review Process. Table 2 provides definitions for each of the categories, as well as some examples for each of them.

The result of this coding process shows that the prestige of academic journals is, in a

11 somewhat circular fashion, most commonly defined by their reputation, which is related to the

12 name recognition of the journal, the people who publish in it or the people in charge of the

13 review process (Figure 2). This was exemplified by definitions like "well-regarded by others in a

14 field" [719], "the journal has a known name in my field of study" [1565] or "well regarded with

15 global recognition" [827]. Prestige was also often defined based on Impact Factor and Metrics

16 and by the Review Process used by the journal. 
1 Table 2. Categories identified in the definitions of Prestigious.

2 Name, description and examples of the categories found in participants' definitions of Prestige. Numbers in square

3 brackets represent anonymized identification of participants.

\begin{tabular}{|c|c|c|}
\hline Category & Description of the category & Examples \\
\hline $\begin{array}{l}\text { Impact factor } \\
\text { and metrics }\end{array}$ & $\begin{array}{l}\text { Established measurement for the journals } \\
\text { by the articles that are published, and the } \\
\text { citation generated }\end{array}$ & $\begin{array}{l}\text { (]) Highly ranked [561] } \\
\text { [? Super impact factor and circulation [761] }\end{array}$ \\
\hline Value & $\begin{array}{l}\text { Scientific rigor and applicability of the } \\
\text { articles published in the journal. }\end{array}$ & $\begin{array}{l}\text { - } \quad \text { Field changing, important, correct [488] } \\
\text { - Usually very good quality [1351] }\end{array}$ \\
\hline Readership & $\begin{array}{l}\text { Focuses on how much the published work } \\
\text { is read by academic and non-academic } \\
\text { people }\end{array}$ & $\begin{array}{ll}- & \text { Widely read [1171] } \\
- & \text { Large reading audience [86] }\end{array}$ \\
\hline $\begin{array}{r}\text { Relation to } \\
\text { associations }\end{array}$ & $\begin{array}{l}\text { Relation of the journal to organizations } \\
\text { that support its operation. }\end{array}$ & $\begin{array}{l}\text { - Association sponsored [812] } \\
\text { - } \quad \text { Affiliated with a widely recognized } \\
\text { organization [577] }\end{array}$ \\
\hline Reputation & $\begin{array}{l}\text { Recognition of the journal itself, the } \\
\text { authors of the articles published in the } \\
\text { journal or the authors citing the journal. }\end{array}$ & $\begin{array}{l}\text { - } \quad \text { High name recognition [581] } \\
\text { - } \quad \text { Held in high regard by researchers [214] }\end{array}$ \\
\hline $\begin{array}{l}\text { Review } \\
\text { process }\end{array}$ & $\begin{array}{l}\text { Elements related to the process of } \\
\text { reviewing the articles that are published, } \\
\text { such as editors, feedback and rejection } \\
\text { rate }\end{array}$ & $\begin{array}{l}\text { - } \quad \text { Expert peer-review [388] } \\
\text { - } \quad \text { Hard to get accepted for publication } \\
\text { [365] }\end{array}$ \\
\hline
\end{tabular}

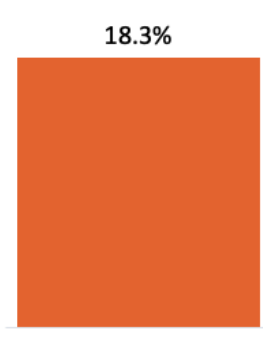

Impact factor and metrics

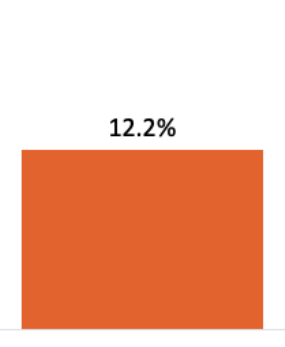

Value

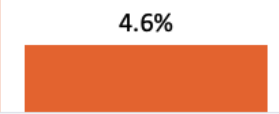

Readership
$42.7 \%$

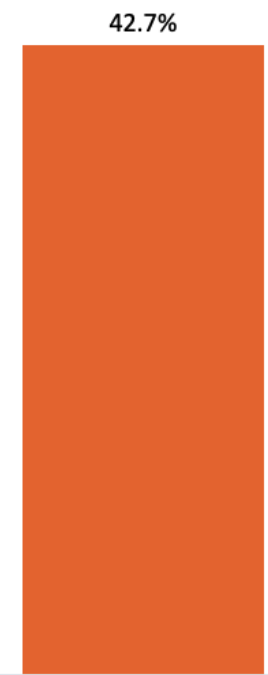

Relation to associations

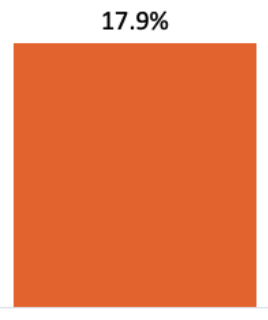

Reputation

Review process

Figure 2. Definitions of Prestige.

6 Percentage of responses that contained at least one segment in each of the categories identified in participants'

7 definitions of Prestige. 
Finally, the analysis of the definitions provided for high impact resulted in 242 segments.

These segments were coded under six categories: Impact Factor and Metrics, Impact on Academia, Impact Outside Academia, Quality, and Readership. Table 3 provides definitions for each of the categories, as well as some examples for each of them.

The result of this coding process shows that high impact is defined by the JIF or other citation metrics in almost half of all instances (Figure 3). Definitions in this category included:

7 "some factor that assess the impact" [581], "number of citations/ papers" [478] or "Interplay

8 between Impact Factor and number of cites per year" [500]. To a lesser extent, High Impact was

9 defined by the volume of readership the research receives and by the impact that the work had on practice, public policy, or in the media.

Table 3. Categories identified in the definitions of High Impact. square brackets represent anonymized identification of participants.

\begin{tabular}{|c|c|c|}
\hline Category & Description of the category & Examples \\
\hline $\begin{array}{r}\text { Impact factor and } \\
\text { metrics }\end{array}$ & $\begin{array}{l}\text { Established measurement for } \\
\text { the journals by the articles that } \\
\text { are published, and the citation } \\
\text { generated }\end{array}$ & $\begin{array}{l}\text { - Interplay between Impact Factor and } \\
\text { number of cites per year [500] } \\
\text { - Use of impact factor to identify a } \\
\text { journal's worthiness [862] }\end{array}$ \\
\hline Impact on academia & $\begin{array}{l}\text { Relevance and influence of the } \\
\text { articles on future research }\end{array}$ & $\begin{array}{l}\text { - Immediately impacting the next work } \\
\text { to be published [583] } \\
\text { - Influences a lot of other researchers } \\
\text { [391] }\end{array}$ \\
\hline Impact outside academia & $\begin{array}{l}\text { Impact on practices and public } \\
\text { policies by the articles, as well } \\
\text { as replicability on media outlets }\end{array}$ & $\begin{array}{l}\text { - Immediate impact on practice [1256] } \\
\text { - Impact on policy \& practice [478] }\end{array}$ \\
\hline Quality & $\begin{array}{l}\text { Scientific rigor and applicability } \\
\text { of the articles published in the } \\
\text { journal. }\end{array}$ & 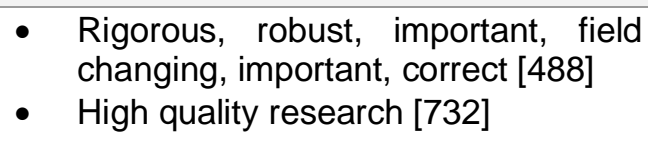 \\
\hline Readership & $\begin{array}{l}\text { Focuses on how much the } \\
\text { published work is read by } \\
\text { academic and non-academic } \\
\text { people }\end{array}$ & $\begin{array}{l}\text { - High readership, broad readership } \\
\text { - } \quad \text { Read widely [1171] }\end{array}$ \\
\hline
\end{tabular}


$49.2 \%$

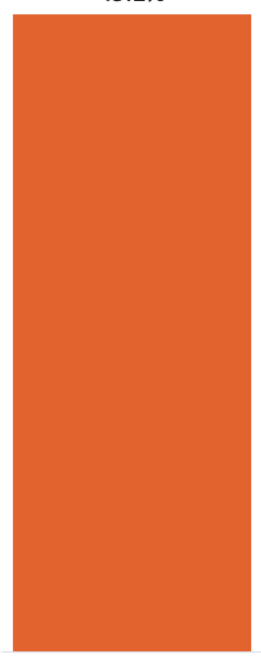

Impact factor and metrics

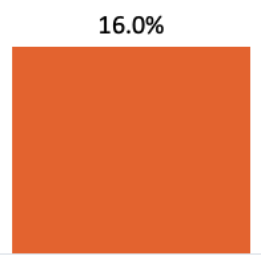

Impact on academia

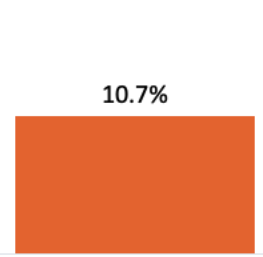

Impact outside academia

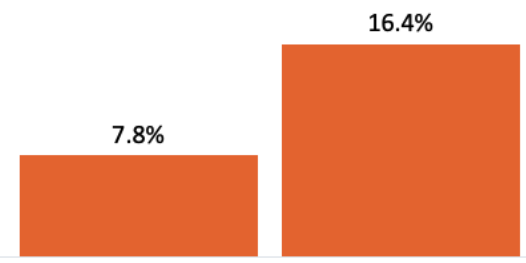

Quality

Readership

Figure 3. Definitions of High Impact.

3 Percentage of responses that contained at least one segment in each of the categories identified in participants'

4 definitions of High Impact.

\section{Differences by demographics}

We performed a Chi-Square test on the definitions of the three terms to understand if

7 they varied depending on the gender, age, and academic discipline of the faculty member or

8 according to the institution type to which they belong (R-type or M-type). The definitions

9 provided by surveyed faculty do not have significant variation in any of these categories, which

10 implies that the academics conceive of these terms irrespective of their gender, age, academic

11 discipline or type of institution in which they are employed (Table 4 and Table 5). 
1 Table 4. Breakdown of definitions by demographic characteristics. Overview of the participants' 2 definition of Quality, Prestige and Impact by their gender, institution type, and age.

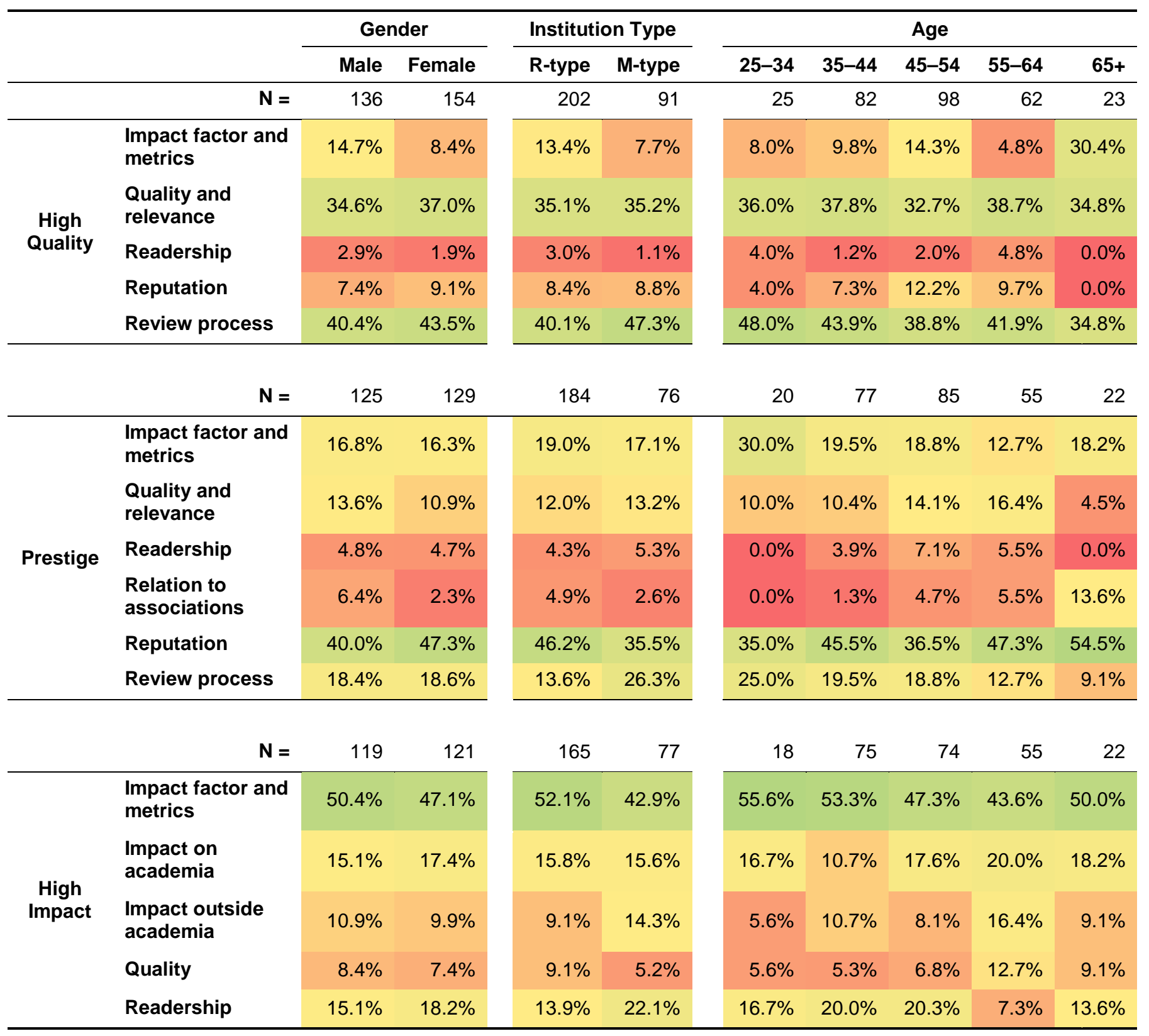


1 Table 5. Breakdown of definitions by demographic characteristics. Overview of the participants'

2 definition of Quality, Prestige and Impact by discipline.

\begin{tabular}{|c|c|c|c|c|c|}
\hline & & \multicolumn{4}{|c|}{ Discipline } \\
\hline & & $\begin{array}{r}\text { Multi- } \\
\text { disciplinary }\end{array}$ & $\begin{array}{r}\text { Social } \\
\begin{array}{r}\text { Sciences and } \\
\text { Humanities }\end{array} \\
\end{array}$ & $\begin{array}{r}\text { Physical } \\
\text { Sciences and } \\
\text { Mathematics }\end{array}$ & Life Sciences \\
\hline & $\mathbf{N}=$ & 30 & 142 & 55 & 63 \\
\hline \multirow{6}{*}{$\begin{array}{l}\text { High } \\
\text { Quality }\end{array}$} & $\begin{array}{l}\text { Impact factor and } \\
\text { metrics }\end{array}$ & $16.7 \%$ & $11.3 \%$ & $7.3 \%$ & $14.3 \%$ \\
\hline & $\begin{array}{l}\text { Quality and } \\
\text { relevance }\end{array}$ & $40.0 \%$ & $36.6 \%$ & $32.7 \%$ & $34.9 \%$ \\
\hline & Readership & $0.0 \%$ & $2.1 \%$ & $3.6 \%$ & $3.2 \%$ \\
\hline & Reputation & $10.0 \%$ & $9.2 \%$ & $12.7 \%$ & $3.2 \%$ \\
\hline & Review process & $33.3 \%$ & $40.8 \%$ & $43.6 \%$ & $44.4 \%$ \\
\hline & $\mathbf{N}=$ & 24 & 130 & 47 & 58 \\
\hline \multirow{7}{*}{ Prestige } & $\begin{array}{l}\text { Impact factor and } \\
\text { metrics }\end{array}$ & $16.7 \%$ & $18.5 \%$ & $12.8 \%$ & $24.1 \%$ \\
\hline & $\begin{array}{l}\text { Quality and } \\
\text { relevance }\end{array}$ & $12.5 \%$ & $13.1 \%$ & $17.0 \%$ & $6.9 \%$ \\
\hline & Readership & $4.2 \%$ & $5.4 \%$ & $4.3 \%$ & $3.4 \%$ \\
\hline & $\begin{array}{l}\text { Relation to } \\
\text { associations }\end{array}$ & $4.2 \%$ & $3.8 \%$ & $6.4 \%$ & $3.4 \%$ \\
\hline & Reputation & $45.8 \%$ & $37.7 \%$ & $44.7 \%$ & $51.7 \%$ \\
\hline & Review process & $16.7 \%$ & $21.5 \%$ & $14.9 \%$ & $10.3 \%$ \\
\hline & $\mathbf{N}=$ & 22 & 125 & 45 & 52 \\
\hline \multirow{5}{*}{$\begin{array}{l}\text { High } \\
\text { Impact }\end{array}$} & $\begin{array}{l}\text { Impact factor and } \\
\text { metrics }\end{array}$ & $40.9 \%$ & $51.2 \%$ & $55.6 \%$ & $42.3 \%$ \\
\hline & $\begin{array}{l}\text { Impact on } \\
\text { academia }\end{array}$ & $27.3 \%$ & $12.8 \%$ & $22.2 \%$ & $13.5 \%$ \\
\hline & $\begin{array}{l}\text { Impact outside } \\
\text { academia }\end{array}$ & $18.2 \%$ & $10.4 \%$ & $6.7 \%$ & $11.5 \%$ \\
\hline & Quality & $4.5 \%$ & $11.2 \%$ & $0.0 \%$ & $7.7 \%$ \\
\hline & Readership & $9.1 \%$ & $14.4 \%$ & $15.6 \%$ & $25.0 \%$ \\
\hline
\end{tabular}

\section{Differences by RPT guidelines}

Finally, given the importance that academics give to the JIF and other metrics to define

5 high quality, prestige, and high impact, we compared the responses received in the survey with

6 the RPT documents from the academic units of the respondent. In particular, we performed a

7 Chi-Square test to see if respondents used a definition coded as "Impact Factor and Metrics" for

8 each of the terms any differently if they worked at academic units that mentioned the JIF and 
related terms in their RPT document. Figure 4 shows the prevalence of this definition among the two groups of faculty (those part of academic units that mention the JIF and those who do not).

3 We do not find statistically significant differences between these groups $\left[X_{2}=(5, N=202)=\right.$

$40.85, p>$.05], indicating that the mention of the JIF and related terms in RPT documents does

5 not affect how faculty define high quality, high impact, and prestige.

JIF not mentioned in guideline

m JIF mentioned in guideline
$63.3 \%$

$58.7 \%$

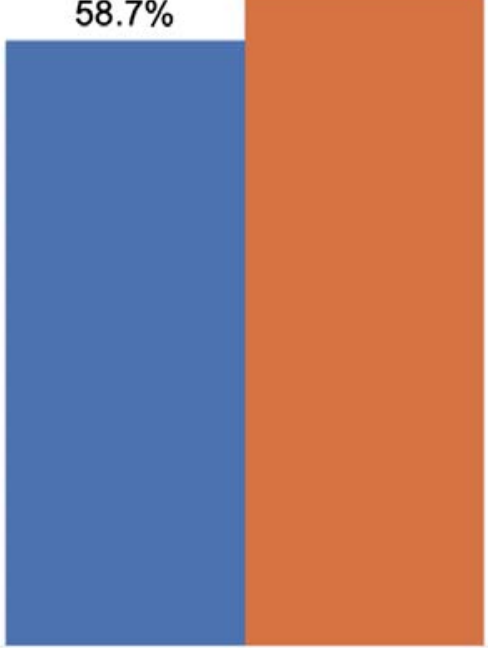

High Impact
High Quality
$16.7 \%$

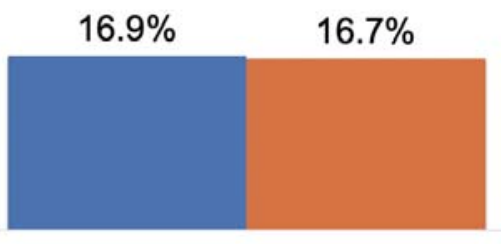

Figure 4. Use of "Impact Factor and Metrics" as a definition of various terms

Percentage of responses that contained at least one segment in participants' definitions of High Quality, Prestige and High Impact that relies on "Impact Factor and metrics", as a proportion of all the RPT guidelines that mentioned the JIF and of the guidelines that did not.

Our analysis of how faculty define quality, impact and prestige, suggests three important outcomes. First, it shows that these three terms, despite referring to three very different concepts, are often defined in overlapping ways (with references to each other and to themselves). Second, it shows that individual faculty members apply very different definitions to each of the terms, with no single definition used by over $50 \%$ of respondents for any of the three terms. Finally, the marked variance in definitions across faculty does not correspond to demographic characteristics, such as the age, gender, discipline nor to characteristics of the institution for which they work, including mentions of the JIF in their academic unit's RPT guidelines. 
While it is known that there is a lack of definitions for many of the terms and concepts used in research assessment (Dean et al., 2016; Hatch, 2019; Moore et al., 2017; van Mil \& Henman, 2016), this study explores how three key terms are understood by faculty in absence of these definitions. Specifically, our results indicate that the concepts of quality, impact, and prestige are often seen as synonymous by faculty, with high quality being sometimes defined by reputation, which is itself one of the most common definitions given for prestige; similarly, high impact is at times defined by quality, and high quality is at times defined by the impact factor. In

8 fact, all three terms - quality, impact, and prestige - are defined through the use of the Impact

9 Factor and other citation metrics by some faculty (with the term Impact itself defined in this way nearly half the time).

Given the subjective nature of these concepts and the overlapping definitions provided by faculty, it is perhaps unsurprising to see that, in all three cases, some faculty resort to the use of quantitative citation metrics as the basis for their definition. The rise in the use of metrics in research assessment has been well documented (Aung et al., 2019; Wilsdon et al., 2015), including in our own work that showed their prevalence in RPT documents and guidelines (Alperin et al., 2019; McKiernan et al., 2019). In this sense, our study confirms that some faculty believe that quality, impact, and prestige can be understood through citation metrics. However, contrary to our hypothesis that faculty would be more likely to think in terms of metrics if they were mentioned in the RPT guidelines for their institution, our study showed that respondents were no more or less likely to use citation metrics in their definitions when this was the case. In other words, despite their importance in determining individual career advancement, the mention of the JIF in RPT guidelines is not correlated with how faculty define quality, impact, or prestige.

This, of course, only raises further questions about how faculty arrive at their understanding of quality, impact, and prestige. While our study does not offer direct answers to these questions, it does point to the wide range of definitions that are currently used by faculty when considering these career-determining aspects of research. Our study shows that in the absence of common definitions, faculty are applying their own understanding of each term and are doing so in ways that differ from their own colleagues. This may stem from their own personal experiences with certain journals, reviewers, editors, and colleagues. For example, the highest percent of respondents in our survey perceived quality as being related to the review

32 process of a journal. However, most journals do not make article reviews public, suggesting 33 that the review process of a journal is not widely known or understood by people outside their 
own experiences. As it is widely documented that the peer review process can vary significantly, this highlights how personal experiences may affect how people perceive these different terms. This is precisely the situation that Hatch (2019) warns could lead to biases (conscious or not) in evaluation processes and could explain in part why faculty are generally unsure of what is expected of them for tenure (DeSanto \& Nichols, 2017).

More broadly, our findings present a challenge for those seeking the most effective ways to bring about research evaluation reform. Unfortunately, our initial exploration suggests that the pathway for making changes to research assessment may not be as simple as clarifying how definitions are presented in assessment guidelines, given that the inclusion of metrics-related terms in RPT documents was not a determining factor in whether faculty used citation metrics in defining high quality, impact, or high prestige. This is not to say that such changes would not be worthwhile; guidelines, like policies and mandates, are an important way for departments and institutions to signal their values, even when those guidelines are not strictly adhered to. However, our research points to the need for additional cultural and environmental factors that determine faculty thinking that cut across age, gender, institution types, and disciplines.

The reliance on metrics shown throughout this study further highlights how terms such as JIF have come to be seen as a way of objectively assessing quality, impact and prestige. This is problematic as it fails to account for the numerous limitations and biases that are present in the creation and implementation of such metrics (Brembs et al., 2013; Haustein \& Larivière, 2015; Sugimoto \& Larivière, 2018) In this sense, it is worth recognizing how efforts towards responsible metrics_advanced by organizations such as DORA, Leiden and HuMetricSS—may indeed help us to move away from the most problematic uses of metrics that are laden with the same challenges as ambiguous definitions.

Results of this study further highlight the need to more clearly implement evaluation regimes that don't rely on ill-defined concepts - which we show are widely subjective and variable- like those discussed here. Indeed, while we acknowledge the complexity of academic careers, these findings demonstrate that when terms such as "high quality, impact and prestige" are used in the context of research and journals, people perceive these differently. As such, it suggests that the use of such terms may lead academics in many directions, which may result in inconsistent outcomes, all of which could be judged differently by RPT committees. The findings of this study invite us to reconsider how, if at all, and with what definitions, we want quality, impact, and prestige to be critical components of research assessment. 


\section{References}

2 Acker, S., \& Webber, M. (2016). Discipline and publish: The tenure review process in Ontario

$3 \quad$ universities. In Assembling and Governing the Higher Education Institution (pp. 233-

4 255). Palgrave Macmillan, London. https://doi.org/10.1057/978-1-137-52261-0_13

5 Aksnes, D. W., Langfeldt, L., \& Wouters, P. (2019). Citations, Citation Indicators, and Research

6 Quality: An Overview of Basic Concepts and Theories. SAGE Open, 9(1), 215824401982957. https://doi.org/10.1177/2158244019829575

Alperin, J. P., Muñoz Nieves, C., Schimanski, L. A., Fischman, G. E., Niles, M. T., \& McKiernan, E. C. (2019). How significant are the public dimensions of faculty work in review, promotion and tenure documents? ELife, 8. https://doi.org/10.7554/eLife.42254

Alperin, J. P., Muñoz Nieves, C., Schimanski, L., McKiernan, E. C., \& Niles, M. T. (2018). Terms and Concepts found in Tenure and Promotion Guidelines from the US and Canada [Data set]. https://doi.org/10.7910/DVN/VY4TJE

Aung, H. H., Zheng, H., Erdt, M., Aw, A. S., Sin, S. J., \& Theng, Y. (2019). Investigating familiarity and usage of traditional metrics and altmetrics. Journal of the Association for Information Science and Technology, 70(8), 872-887. https://doi.org/10.1002/asi.24162

Belcher, B., \& Palenberg, M. (2018). Outcomes and Impacts of Development Interventions: https://doi.org/10.1177/1098214018765698 
Academe. Human Performance, 27(2), 99-128. https://doi.org/10.1080/08959285.2014.882925

Blankstein, M., \& Wolff-Eisenberg, C. (2019). Ithaka S+R US Faculty Survey 2018 (p. 70).

Brembs, B. (2018). Prestigious Science Journals Struggle to Reach Even Average Reliability. Frontiers in Human Neuroscience, 12. https://doi.org/10.3389/fnhum.2018.00037

Brembs, B., Button, K., \& Munafò, M. (2013). Deep impact: Unintended consequences of journal rank. Frontiers in Human Neuroscience, 7, 291.

Cagan, R. (2013). The San Francisco Declaration on Research Assessment. Disease Models \& https://doi.org/10.3389/fnhum.2013.00291

Carnegie Community Engagement Classification. (n.d.). Campus Compact. Retrieved January 10, 2019, from https://compact.org/initiatives/carnegie-community-engagement-

Chapman, C. A., Bicca-Marques, J. C., Calvignac-Spencer, S., Fan, P., Fashing, P. J., Mechanisms, 6(4), 869-870. https://doi.org/10.1242/dmm.012955

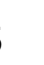

$$
\text { Gogarten, J., Guo, S., Hemingway, C. A., Leendertz, F., Li, B., Matsuda, I., Hou, R., }
$$
Serio-Silva, J. C., \& Chr. Stenseth, N. (2019). Games academics play and their consequences: How authorship, $h$-index and journal impact factors are shaping the

20 Chen, C. Y. (2015). A Study Showing Research Has Been Valued over Teaching in Higher

$21 \quad$ Education. Journal of the Scholarship of Teaching and Learning, 15-32. https://doi.org/10.14434/josotl.v15i3.13319 
1 Dean, E., Elardo, J., Green, M., Wilson, B., \& Berger, S. (2016). The importance of definitions. In Principles of Microeconomics: Scarcity and Social Provisioning. Open Oregon.

DeSanto, D., \& Nichols, A. (2017). Scholarly Metrics Baseline: A Survey of Faculty Knowledge, Use, and Opinion about Scholarly Metrics. College \& Research Libraries, 78(2), 150170. https://doi.org/10.5860/crl.78.2.150

DORA. (n.d.). Good Practices - Funders - DORA. San Francisco Declaration on Research Assessment. Retrieved September 17, 2018, from https://sfdora.org/good-

Edwards, M. A., \& Roy, S. (2017). Academic Research in the 21st Century: Maintaining practices/funders/

Fox, J. W. (2012). Can blogging change how ecologists share ideas? In economics, it already has. Ideas in Ecology and Evolution, 5(2), 74-77. https://doi.org/10.4033/iee.2012.5b.15.f Scientific Integrity in a Climate of Perverse Incentives and Hypercompetition. Environmental Engineering Science, 34(1), 51-61. https://doi.org/10.1089/ees.2016.0223 
1 Gordon, C. K. (2008). Organizational rhetoric in the academy: Junior faculty perceptions and roles [University of North Texas]. http://digital.library.unt.edu/ark:/67531/metadc9779/m2/1/high_res_d/thesis.pdf

Gruzd, A., Staves, K., \& Wilk, A. (2011). Tenure and promotion in the age of online social media. Proceedings of the American Society for Information Science and Technology,

Harley, D., Acord, S. K., Earl-Novell, S., Lawrence, S., \& King, C. J. (2010). Assessing the 48(1), 1-9. https://doi.org/10.1002/meet.2011.14504801154

Hatch, A. (2019). To fix research assessment, swap slogans for definitions. Nature. future landscape of scholarly communication: An exploration of faculty values and needs in seven disciplines. Center for Studies in Higher Education. http://escholarship.org/uc/item/15x7385g

Haustein, S., \& Larivière, V. (2015). The use of bibliometrics for assessing research: Possibilities, limitations and adverse effects. In Incentives and Performance (pp. 121-

Hicks, D., Wouters, P., Waltman, L., de Rijcke, S., \& Rafols, I. (2015). Bibliometrics: The Leiden Manifesto for research metrics. Nature News, 520(7548), 429.

Howard, J. (2013). Rise of "altmetrics" revives questions about how to measure impact of research. The Chronicle of Higher Education, 59(38), A6-A7. 
Maclean's Rankings. (n.d.). Retrieved September 17, 2018, from https://www.macleans.ca/education/unirankings/

McHugh, M. L. (2012). Interrater reliability: The kappa statistic. Biochemia Medica, 276-282. https://doi.org/10.11613/BM.2012.031

McKiernan, E. C., Schimanski, L. A., Muñoz Nieves, C., Matthias, L., Niles, M. T., \& Alperin, J. P. (2019). Use of the Journal Impact Factor in academic review, promotion, and tenure evaluations. ELife, 8, e47338. https://doi.org/10.7554/eLife.47338

Miller, J. E., \& Seldin, P. (2014). Changing Practices in Faculty Evaluation: Can better evaluation make a difference? AAUP. https://www.aaup.org/article/changing-practices-

Moher, D., Naudet, F., Cristea, I. A., Miedema, F., loannidis, J. P. A., \& Goodman, S. N. (2018). Assessing scientists for hiring, promotion, and tenure. PLOS Biology, 16(3), e2004089.

Moore, S., Neylon, C., Paul Eve, M., Paul O’Donnell, D., \& Pattinson, D. (2017). “Excellence R Us": University research and the fetishisation of excellence. Palgrave Communications,

Munafò, M. R., Stothart, G., \& Flint, J. (2009). Bias in genetic association studies and impact factor. Molecular Psychiatry, 14(2), 119-120. https://doi.org/10.1038/mp.2008.80

Niles, M. T., Schimanski, L. A., McKiernan, E. C., \& Alperin, J. P. (2020). Why we publish where we do: Faculty publishing values and their relationship to review, promotion and tenure expectations. PLOS ONE, 15(3), e0228914. https://doi.org/10.1371/journal.pone.0228914 
1 Open Science Collaboration. (2015). Estimating the reproducibility of psychological science. Science, 349(6251), aac4716. https://doi.org/10.1126/science.aac4716

Piwowar, H. (2013). Altmetrics: Value all research products. Nature, 493(7431), 159-159.

Rice, D. B., Raffoul, H., loannidis, J. P. A., \& Moher, D. (2020). Academic criteria for promotion and tenure in biomedical sciences faculties: Cross sectional analysis of international sample of universities. BMJ, m2081. https://doi.org/10.1136/bmj.m2081

Sanberg, P. R., Gharib, M., Harker, P. T., Kaler, E. W., Marchase, R. B., Sands, T. D., Arshadi, N., \& Sarkar, S. (2014). Changing the academic culture: Valuing patents and

Schimanski, L., \& Alperin, J. P. (2018). The evaluation of scholarship in the academic promotion and tenure process: Past, present, and future. F1000Research. https://doi.org/10.12688/f1000research.16493.1

Snider, A., Hight, K., Brunson, A., Payakachat, N., \& Franks, A. M. (2020). Qualitative Content commercialization toward tenure and career advancement. Proceedings of the National Academy of Sciences, 111(18), 6542-6547. https://doi.org/10.1073/pnas.1404094111

Strauss, A., \& Corbin, J. (1990). Basics of Qualitative Research. Sage publications.

19 Sugimoto, C. R., \& Larivière, V. (2018). Measuring research: What everyone needs to know. Oxford University Press. 
1 Szucs, D., \& loannidis, J. P. A. (2017). Empirical assessment of published effect sizes and power in the recent cognitive neuroscience and psychology literature. PLoS Biology, 15(3), e2000797. https://doi.org/10.1371/ journal.pbio.2000797

van Mil, J. W. F., \& Henman, M. (2016). Terminology, the importance of defining. International Journal of Clinical Pharmacy. https://doi.org/10.1007/s11096-016-0294-5

Vinyard, M., \& Colvin, J. B. (2018). How research becomes impact: Librarians helping faculty use scholarly metrics to select journals. College \& Undergraduate Libraries, 25(2), 187204. https://doi.org/10.1080/10691316.2018.1464995

9 Wilsdon, J., Allen, L., Belfiore, E., Campbell, P., Curry, S., Hill, S., Jones, R., Kain, R., Kerridge, S., Thelwall, M., Tinkler, J., Viney, I., Wouters, P., Hill, J., \& Johnson, B. (2015). The Metric Tide: Report of the Independent Review of the Role of Metrics in Research 